\title{
'We didn't be there for networking'. How French elite schools alumnis activate their relational ressources?
}

\author{
Pierre Bataille, LaRAC, Université Grenoble-Alpes \\ Virtual Sunbelt conference 2020 (16th July)
}

\begin{abstract}
Sociological or historical surveys on French elites highlighted at many occasions that "grandes écoles" graduated are over-represented at the top of the socio-professional hierarchy. These surveys showed that social capital constituted by passing through an elite higher educational institution and the co-optation networks among graduates from the same institution is a key asset to reach these prestigious social positions. But little is know on the concrete activation conditions of such relational resources. Focusing on one "grandes écoles" graduates subgroup (the graduates from one of the Ecole Normale Supérieure), our presentation aims to better understand how social capital is activated. Based on in-depth interview analysis and alumni associations archives analysis, we try to shed a light on the activation conditions of such relational school-based resources in diverse professional contexts. On the one hand, we show that crossing the analysis of the legitimate definition of the social link among the graduates and the norms and representations that structure the professional groups reached by graduates is a key insight to understand the relational resources activation possibilities. On the other, we analyze how the struggle within the alumni group to fix the " good » way of define school-based relational resources frame the activation possibilities of such resources.
\end{abstract}

\section{Intro and research question}

My name is Pierre Bataille and today, I would like to share with you some outcomes of my PhD Thesis on the life courses of elite school gradutates in France - especially they use of the social capital build on this elite school alumni label. The result I present today are from an already published article (2019).

As you may know, in France as in UK or in the USA, alumni of the the most prestigious universities/college benefit of many assets to get the top professional positions.

Among all, they are supposed to be de facto inserted in large and strong networks of former student, professors, etc... that will be a key resource in their career development.

My point is that to understand the power of relational resources on elite production or reproduction, one have to focus on the way connections are activated by people in regard to the context. Indeed, many works on elites network mobilize only a structural approach: they analyze the objective links between elites member through the interlocking of institutions, firms, political parties, etc... Following Bruno Cousin and Sébastien Chauvin argument (Cousin \& Chauvin, 2012, 2014), I think that such approach is not sufficient to understand how network become social capital. To get how network is turn into effective resource, one must also focus on the "symbolic economy" of such network, I.e how people embedded in elite spaces represent them self what is a "good" or a "true" social capital and how its shape the activation of relational resources.

For instance, imagine that you are in some of the oldest club in town, where members of nobility meets discuss about their business around a glass of whisky. Imagine if a young manager get into this club and starting by distribute his business card, tell everyone that he is only here for networking, to enhance his

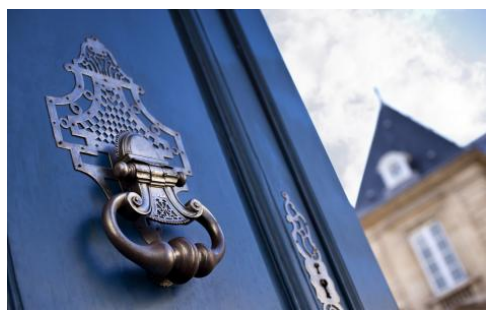

Fig1. The "Grandes Ecoles" or the higway to professionnal success 


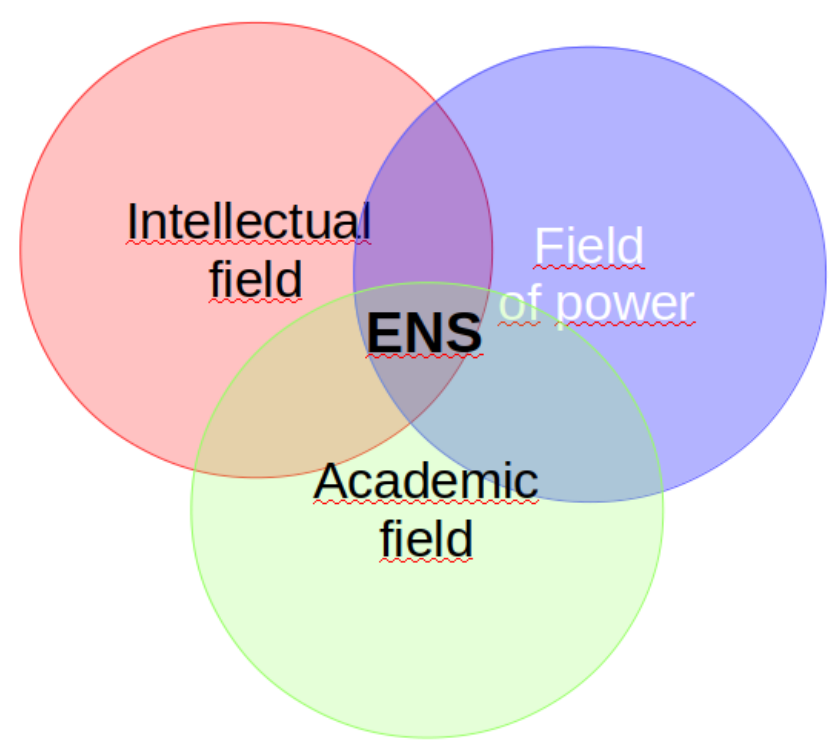

Fig2. The ENS at the crossroad

personal address book. No doubt that he will seems not enough distinguished, not enough discrete, etc... and, that, finally he can't transform his access to potential relational resources into effective "social capital". Here you have two definition of what is a "good" social capital: on the one hand (in the old club), a "good" and effective social capital have to be uninterested, discrete, respectful of certain tradition; on the other hand (for the young manager), a "good" and effective capital is more a link that you can bridge with another aiming to gain a more valuable and central position in the network, in line with the "address book" rhetoric.

In other words, transforming ties into "social capital" needs to follow some socio-symbolic tacit rules. That is this rules I try to point out in my work - especially the rules of relational resources activation in academic context. So my main research question is "Is there more efficient ways in activating relational resources for French educational elites regarding their professional position?"

\section{Data}

In my thesis, I have been focused on the life course of Ecole Normale Supérieur (or ENS) alumni, class of 1981 to 1987. As you may know, French ENS are at the crossroad of three field (Bourdieu, 1998; Rubenstein, 1990): the academic field, the field of power and the intellectual field (Fig. 2). Thus "normaliens" often become academics or secondary teacher, sometimes senior civil servant or manager in a big firm and more rarely artist, journalist etc., as shown in Figure 3. Because they feel "out of step" regarding their ex classmates, this non-academic alumni often describe themselves as "deviated".

In my thesis, I used a mixed-methods research design. I ran a questionnaire survey (mail and letter) that I sent to the 1600 people of ENS of Fontenay \& Saint Cloud, classes of 1981 to 1987. I get a response rate of $38 \%$, that is not that bad. For more information on the results of this questionnaire survey, see my papers thereafter $(2015,2017)$.

I did an archive-based research, by analyzing the alumni associations official publications between 1980 and 2000 .

I also did an interview survey with 50 alumni from these ENS. This interviews are the main material my today presentation is based upon. 


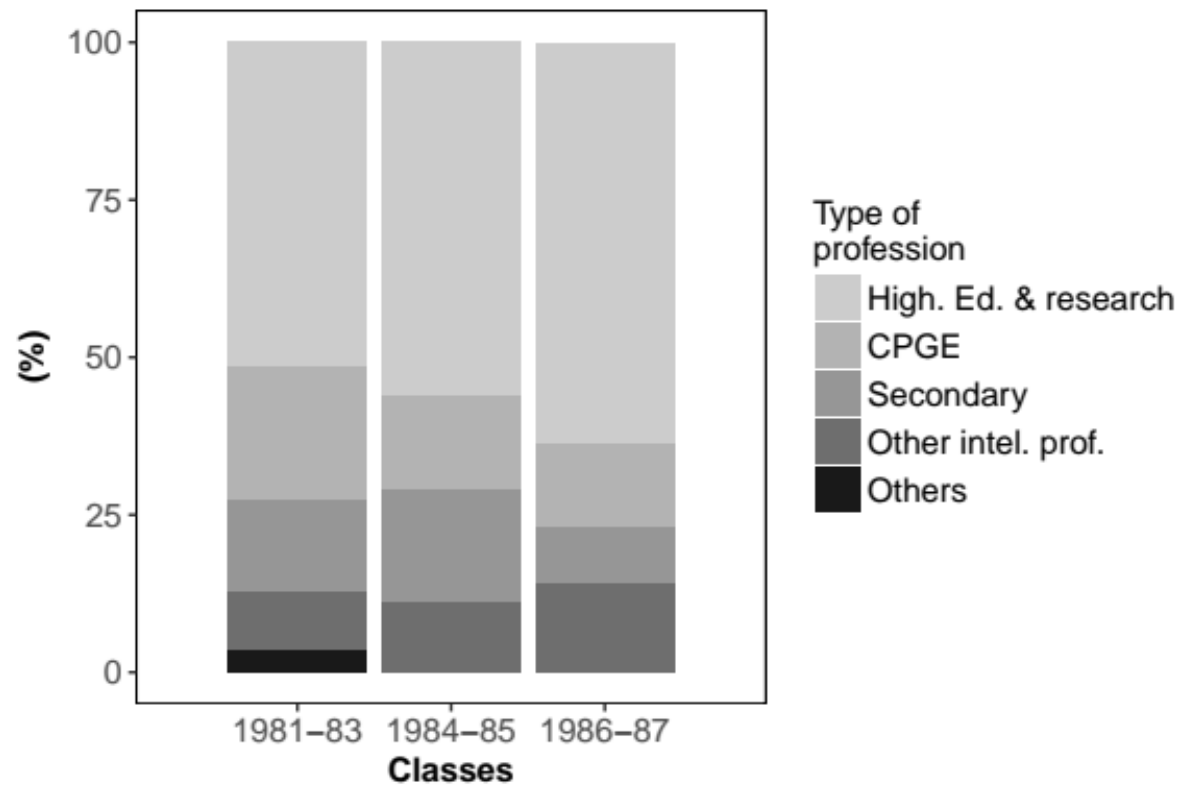

Fig3. Occupations of ENS alumni in 2010 (classes of 1981-1987, source: Bataille, 2018)

As I said, my presentation goal is to shed a light on the symbolic conditions of activation of relational resources among elites. For doing so, I will compare the way ENS alumni activate their "dormant ties" (Levin et al., 2010) in academia and when they are senior civil servant or manager. I will follow a two steps demonstration: first I will present you the definition of the "ENS" social capital defended by the alumni associations; second I will present you how this definition match or not with the logic that shape the two considered work environment (academia or administration/firms).

\section{Results}

\section{The normalien's network: "We didn't be there for networking, that's not the spirit"}

When I ask my interviewees if they already directly activate the alumni network in order to find a job or so on, they often answer "We didn't be there for networking" or "networking, that's not the spirit". They also point out that in other grandes écoles, more market-career oriented or more political-career oriented, such as Sciences-Po Paris or HEC, alumni often seek to build a network for their future careers. But in the ENS, it would be different.

To understand such denial of the power of the ENS alumni network, you have to think of the location of the ENS in the grandes écoles field.

As Bourdieu (1998) did note, in the 1980's, the ENS are located at the more "intellectual" and "autonomous" pole of the field of Grandes Ecoles regarding other institutions like ENS, IEP (aka Sciences-Po Paris) or HEC (cf. Fig. 4). Thus, one may think that the critical discourse of our interviewees on the instrumental use of "social capital" that alumni fom IEP or ENA is also a linked with this localization at the "intellectual" and "spiritual pole", where "selflessness" and "gratuity" represent the cardinal values. And the alumni association member are many to protect the ENS network from such instrumental utilization. For instance, they don't organize business meeting or fundraising gala, to help alumni to keep in touch together and to get in touch with personalities from the political/economical fraction of the field of power - as the alumni association of HEC or Sciences-Po does. They organize yearly meeting, mainly to maintain the memory of the institution, 


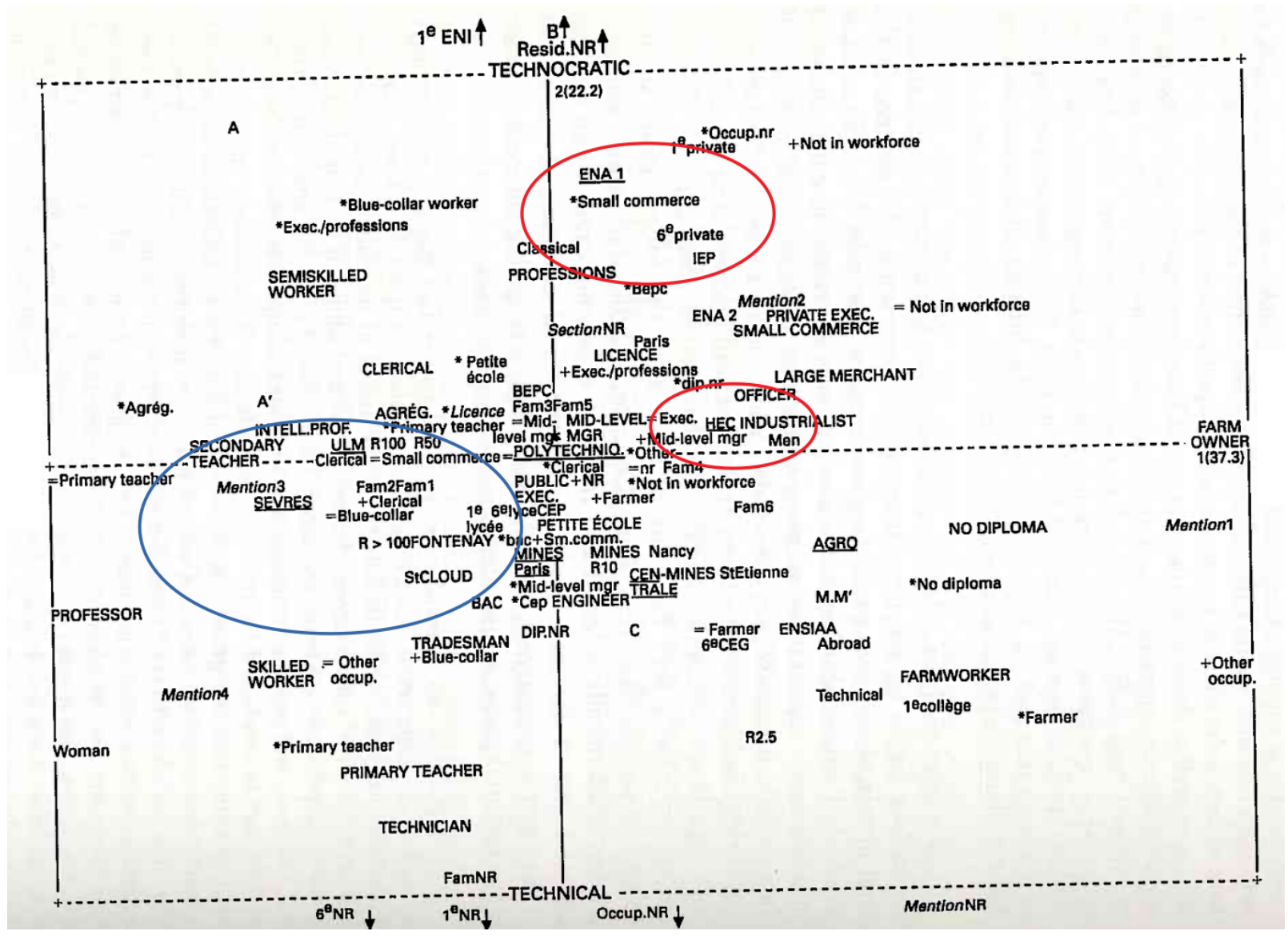

Fig4. The Grandes Ecoles field at the mid 1980's (Bourdieu, 1998)

its link with teaching, etc...

\section{Minimise instrumental activation: the tacit rules of networking}

Thus, when we ask alumni how they activate the alumni network during their careers, their often says they don't feel comfortable for doing so. This is especially the case of those who pursue an academic career.

Indeed, as academic they feel that their career have to be evaluate on scientific criteria and merit, in line with the principles ruling the scientific field (Merton, 1973). They often find ridiculous the idea that they due their professional career to the fact that they where part of an institution such as Grandes Ecole, that reward "cramming" and "social reproduction" as they say in interview. They often admit that they benefited indirectly of the alumni network, but they denial to have directly activate those links.

Thus, in this case, any "good" and "effective" activation have to seems like it wasn't "really" an activation. This is what Bruno, a Professor of English Civilization, says more or less directly:

"[The alumni network] works like in academic conference. It's the same thing. Conference are a place to meet and build its own networks. And the joke that what is important in the conferences are more like coffee breaks and dinners are not fake... This is where the sociability are very, very effective and where teams are formed and can live for as long as the a long, long time." (Bruno, Prof)

And alumni who didn't have this read of the academic game - who often are women and people with low social background - most of the time don't benefit fully of the large ENS alumni "dormant" network in the French Universities. They thus tend to drop out the academic career track (cf. Fig.5). 


\begin{tabular}{|c|c|c|c|c|c|c|c|}
\hline & & Por RD & $L, R$ or PRAG & CPGE & Sec & Oth. Int. Occ. & Total \\
\hline \multirow[t]{2}{*}{ Sex } & Female & 21 & 53 & 44 & 65 & 37 & 44 \\
\hline & Male & 79 & 47 & 56 & 35 & 63 & 56 \\
\hline \multirow[t]{3}{*}{ Soc. Origin } & Underprivileged & 21 & 28 & 38 & 40 & 12 & 28 \\
\hline & Upwardly mobile & 31 & 32 & 31 & 26 & 22 & 30 \\
\hline & Well off & 40 & & 24 & 25 & 59 & 34 \\
\hline
\end{tabular}

Fig.5 Social background and career outcome 1 (source: Bataille, 2018)

\begin{tabular}{llcccccc} 
& & P or RD & L, R or PRAG & CPGE & Sec & Oth. Int. Occ. & Total \\
\hline Sex & Female & 21 & 53 & 44 & 65 & 37 & 44 \\
& Male & 79 & 47 & 56 & 35 & 63 & 56 \\
\multirow{3}{*}{ Soc. Origin } & & & & & & \\
& Underprivileged & 21 & 28 & 38 & 40 & 12 \\
& Upwardly mobile & 31 & 32 & 31 & 26 & 28 \\
& Well off & 40 & 32 & 24 & 25 & 59 & 30 \\
& & & & & & &
\end{tabular}

Fig.6 Social background and career outcome 2 (source: Bataille, 2018)

Narratives of alumni who deviated from the academic career track to pursue a senior civil servant career or manager in private firms strongly differ.

First of all, they are really few ENS alumni in most of the non-academic professional spaces. Thus build a network and find links to activate has often been difficult. In fact, most of these "deviated" alumni followed a double academic curriculum in the ENS and in Sciences-Po. Thus they more often use their Sciences-Po network - and have often no more connection with the ENS at the time or the interview. Since they mainly are from well endowed social background, they also benefit from personal family network to insure the "conversion" of they academic capital into professional asset (cf. Fig.6).

Nevertheless, when they try to activate the alumni network for professional insertion purpose, they also failed because of the symbolic economy of the ENS social capital. David, who is chief editor for a public institution media service after having spent about ten years in the private sector directly after leaving ENS, came up against this fundamental difference in the conception of the ENS social capital. He benefit from the support of a former alumni to get his first job in the human resources department of a well known French newspaper. On the strength of this experience in HR, he offered his services to the alumni association in order to set up tools to better target and visualise the normaliens evolving outside the academic field: The association members did answer that they were "not interested" in issues related to "the professional network in the broad sense" and did not follow up.

So, in order to promote their own definition of what a "good" social capital would be - i.e a social capital more suited for "instrumental" uses than the "intellectual" ones - this "deviated" alumnis create their own association in 1990, which is call "Normal Plus". And the inaugural speech of the association president make no doubt about the purpose of defend the alumni interest by promoting a more effective and instrumental "esprit de corps".

At "Normale Plus", we're not a social club. Our idea is to re-evaluate our training, to show its value, to highlight success, to let people know how we have been able to express ourselves in the most diverse ways. Our basic idea is to avoid the mess our generation has had to endure and to present possible options to those 


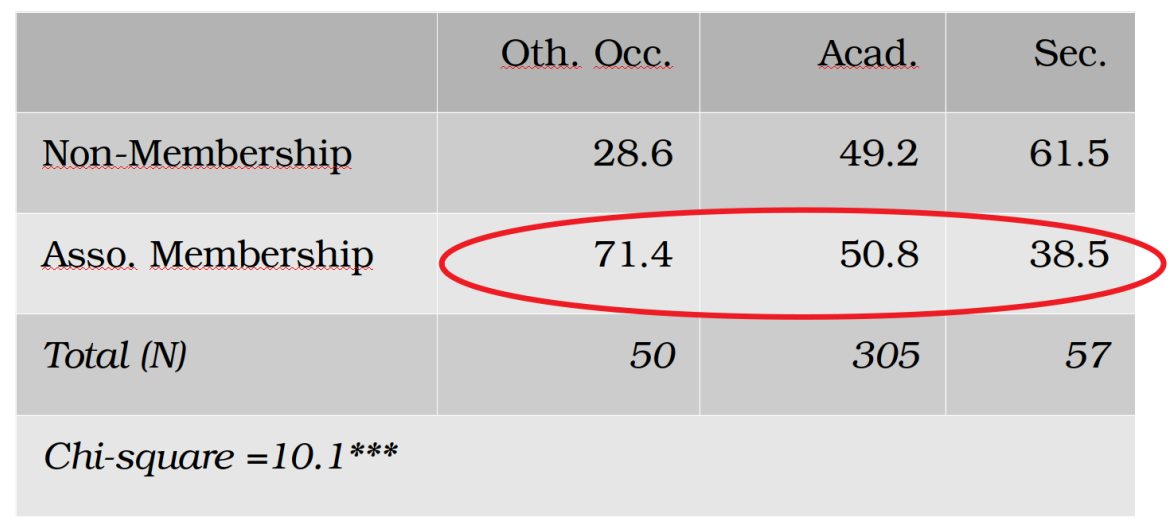

Fig.7 Main alumni association membership and career outcome (source: Bataille, 2019)

who are looking for their way out of teaching and research. We need to be able to wear our title everywhere, not sell it by favouring another school.

They also largely invest the traditional alumni association, in order to pull their weight in the debate on what "being an ENS alumni" means (Fig. 7).

\section{Conclusion}

To conclude, I would like to highlight two main points:

- In line with my results, I think that elite sociology - and more globally debate on social capital - needs more qualitative approach. Indeed, by too much focus on the structure of network, they often miss the fact that interaction between individuals are also of symbolic matters. And the economy of "symbolic interactions" is a key issue to better understand how people get advantage or not from social ties.

- I also would like to open the discussion on the use of network in academia. For my interviewees, it appears clear that the too much instrumental uses of networks (without any reference to the cardinal value of scientific field) is suspicious. In the more and more conccurential and project based academic system that we know today, one may wonder if such "traditional" symbolic economy of academic social capital is still up to date and for how long.

\section{References}

Bataille, P. (2015, November 26). What happened to the queens? Normaliens' career styles at the end of the XXe century in France. Changing Elites in Europe. https://hal.archives-ouvertes.fr/hal-02623896

Bataille, P. (2017). Failed Careers? Sociogenesis and Appropriations of a Bifurcation: The Case of Alumni of the École normale supérieure who Teach in Secondary Education. Biens Symboliques/Symbolic Goods, 1. http://revue.biens-symboliques.net/112

Bataille, P. (2019). "Les réseaux, c'était pas Normale Sup". Les modalités d'activation des ressources relationnelles normaliennes en milieu professionnel. Zilsel, 6, 115-143.

Bourdieu, P. (1998). The state nobility: Elite schools in the field of power. Stanford University Press.

Cousin, B., \& Chauvin, S. (2012). L'Economie symbolique du capital social: Notes pour un programme de recherche. Actes de La Recherche En Sciences Sociales, 193, 93-103.

Cousin, B., \& Chauvin, S. (2014). Globalizing forms of elite sociability: Varieties of cosmopolitanism in Paris social clubs. Ethnic and Racial Studies, 37(12), 2209-2225. 
Levin, D. Z., Walter, J., \& Murnighan, J. K. (2010). Dormant Ties: The Value Of Reconnecting. Organization Science, 22(4), 923-939. https://doi.org/10.1287/orsc.1100.0576

Merton, R. K. (1973). The normative structure of science. In R. K. Merton (Ed.), The sociology of science: Theoretical and empirical investigations (pp. 267-278).

Rubenstein, D. (1990). What's Left? The Ecole Normale Supérieure and the Right. University of Wisconsin Press. 